\title{
ESTIMASI JARAK TEMPUH ORDER PICKING MANUAL DENGAN METODE ANALITIK DI PT GMS
}

\author{
AGUNG CHANDRA \\ Fakultas Teknik, Jurusan Teknik Industri, Universitas Mercubuana \\ Jl. Raya Meruya Selatan no.01, Kembangan, Jakarta Barat 11650 \\ Surel: agungchandra_07@yahoo.co.uk
}

\begin{abstract}
ABSTRAK
Jarak tempuh memegang peranan penting dalam produktivitas pergudangan. Salah satu cara untuk mengetahui jarak tempuh adalah dengan menggunakan metode analitik, estimasi jarak tempuh rata - rata. Pada penelitian di PT GMS ini, strategi routing yang digunakan adalah S-shape atau traversal strategy dan return strategy, sedangkan metode penyimpanan yang digunakan adalah random storage. Komponen estimasi jarak tempuh yang digunakan adalah jarak tempuh dari depot ke pick aisle yang pertama,jarak tempuh yang dilalui pada pick aisle, jarak tempuh balik dalam pick aisle, jarak tempuh pada cross aisle, serta jarak tempuh untuk kembali ke depot. Dari kalkulasi ini, metode S-shape menghasilkan total estimasi jarak tempuh rata-rata sejauh 41,4095 meter, sedangkan metode return strategy sejauh 45,7165 meter.
\end{abstract}

Kata kunci: jarak tempuh, komponen estimasi statistik, routing S-shape, return strategy

\begin{abstract}
Travel distance has a significant role in warehousing productivity. One way to calculate travel distance is to use analytical method, in term of average travel distance. Routing strategy implemented, S-shape I traversal strategy and Return strategy, random storage method are used in this paper at PT.GMS. The components of average travel distance are used to calculate: traveling distance from the depot to the first pick aisle, traveling distance through subaisle with picks, correction of travel distance for turns within subaisle, traveling distance in the cross aisle while picking, traveling distance back to the depot if all picks in one block, and total average travel distance. The results show the total average travel distance using $S$-shape is 41.4095 meter and return strategy is 45.7165 meter.
\end{abstract}

Key words: travel distance, components of statistical estimation, routing $S$-shape, return strategy

\section{PENDAHULUAN}

Perancangan tata letak gudang merupakan suatu hal yang cukup kompleks, hal ini dikarenakan banyak pertimbangan dalam proses perancangan, seperti volume barang, frekuensi pengambilan barang, metode pengambilan barang, kedekatan lokasi, penggolongan penyimpanan barang yang seluruhnya akan berujung pada biaya yang akan dikeluarkan dan produktivitas yang ingin dicapai, atau dengan kata lain efisiensi, efektivitas, dan produktivitas. Perancangan gudang didefinisikan sebagai pendekatan terstruktur untuk pengambilan keputusan pada tingkat strategis, taktis, dan operasional. Keputusan yang memiliki pengaruh jangka panjang, kebanyakan ada pada investasi, seperti perancangan aliran proses dan pemilihan keputusan strategis. Sedangkan keputusan pada tingkat medium atau taktis seperti pengukuran sistem penyimpanan, perancangan tata letak dan pemilihan peralatan. Selanjutnya pada tingkat operasional atau keputusan jangka pendek seperti kebijakan pengendalian gudang (Dukic and Opetuk, 2012).

Pada pergudangan, permasalahan utama pada tata letak gudang adalah mendapatkan tata letak 
yang optimal pada area penyimpanan atau area order picking, di mana kriteria utamanya adalah jarak tempuh (travel distance) atau waktu tempuh (travel time). Waktu tempuh akan bertambah pada saat jarak tempuh bertambah (De Koster et al., 2007). Order Picking merupakan aktivitas yang paling tinggi biayanya dalam pergudangan dan bisa mencapai 55\% dari total biaya operasi pergudangan, sehingga dianggap sebagai prioritas utama dalam peningkatan produktivitas (Tompkins et al., 2010). Order Picking juga merupakan proses yang banyak menggunakan tenaga kerja baik dalam pergudangan yang menggunakan sistem manual ataupun sistem automasi (De Koster et al., 2007). Order Picking merupakan proses pengambilan barang dari lokasi simpan berdasarkan permintaan pelanggan (Dukic and Opetuk, 2008) dan mencakup proses mendapatkan jumlah yang tepat dan produk yang tepat (De Koster et al., 2007).

Dalam pergudangan, permasalahan utama pada tata letak gudang adalah untuk mendapatkan tata letak yang optimal pada area penyimpanan atau area order picking, dimana kriteria utamanya adalah jarak tempuh (travel distance) atau waktu tempuh (travel time). Waktu tempuh akan bertambah pada saat jarak tempuh bertambah (De Koster et al., 2007). Order Picking merupakan aktivitas yang paling tinggi biayanya dalam pergudangan dan bisa mencapai $55 \%$ dari total biaya operasi pergudangan, sehingga dianggap sebagai prioritas utama dalam peningkatan produktivitas (Tompkins et al., 2010; Dukic and Oluic, 2007). Order Picking juga merupakan proses yang banyak menggunakan tenaga kerja baik dalam pergudangan yang menggunakan sistem manual ataupun sistem automasi (De Koster et al., 2007). Order Picking merupakan proses pengambilan barang dari lokasi simpan berdasarkan permintaan pelanggan (Dukic and Opetuk, 2008) dan mencakup proses mendapatkan jumlah yang tepat dan produk yang tepat (De Koster, et al., 2007).

Waktu untuk travel merupakan waktu yang berhubungan dengan perpindahan antar lokasi yang harus dikunjungi di mana barang disimpan dan diambil. Sedangkan waktu picking merupakan waktu yang berhubungan dengan pengambilan barang/grabbing the items, termasuk juga meletakkan barang ke troli, memeriksa pick list dan membaca pick list/lokasi barang yang akan diambil berikutnya. Waktu yang tersisa meliputi aktivitas untuk meletakkan troli, menunggu untuk penugasan berikutnya, sosial, dan lain-lain. Pengurangan jarak dan waktu travel mempunyai pengaruh penting terhadap total waktu untuk melakukan order picking (De Koster et al., 1999). Jarak tempuh dipengaruhi oleh 4 faktor utama (Roodbergen et al., 2008): panjang pick aisles, jumlah pick aisles, jumlah blok, dan jumlah picks per route. Dengan berkurangnya jarak berarti pula berkurangnya juga konsumsi energi, yang disebut greener warehousing. Ada 3 alasan utama mengapa perusahaan mengimplementasikan greening process (Dukic, et al., 2010): perusahaan harus memenuhi peraturan (regulations / legislations) lingkungan, perusahaan harus memenuhi permintaan pelanggan, dan perusahaan dapat meminimalkan pengaruh aktivitas produksi pada lingkungan (ecological awareness).

Jarak tempuh dapat diestimasi dengan menggunakan strategi routing. Strategi routing mempunyai pengaruh langsung terhadap jarak dan waktu tempuh. Strategi routing yang baik bisa mengurangi waktu tempuh secara significant (De Koster et al., 1999). Saat ini di PT GMS, order picking masih berjalan secara random yang berarti pekerja menyiapkan barang di gudang masih belum terarah (pada Gambar 1 bisa dari aisle A, B, ataupun C) dan belum

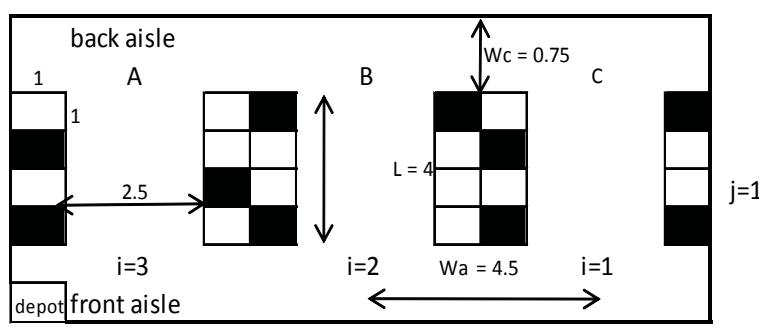

Gambar 1. Layout Gudang PT GMS 
memiliki panduan routing untuk memilih jarak yang terpendek.

Dengan dasar inilah dilakukan penelitian untuk mengetahui strategi routing yang terbaik untuk diterapkan agar didapatkan jarak tempuh yang terpendek. Strategi routing merupakan alat kalkulasi yang digunakan dalam metode analitik. Metode analitik dianggap lebih sederhana untuk diterapkan pada aplikasi spreadsheet.

\section{METODE}

Tahapan memilih jarak yang terpendek, pertama-tama adalah mengeplot tata letak gudang di PT GMS yang akan diteliti, kemudian dari hasil plot, hitung jumlah pick aisle (n), jumlah blok (k), panjang pick aisle (y), jumlah picking yang akan dilakukan $(\mathrm{m})$, lebar cross aisle $\left(W_{c}\right)$, jarak titik tengah ke titik tengah antar 2 pick aisle yang berdekatan, pick aisle yang paling kiri (i), dan blok yang terjauh dari depot (j).

Setelah mendapatkan data tersebut, maka langkah berikutnya adalah menghitung jarak tempuh dengan metode analitik, yaitu strategi routing yaitu S Shape/Traversal dan Return. Kedua strategi tersebut kemudian dibandingkan untuk dipilih jarak tempuh yang terpendek. Jarak tempuh yang terpendeklah yang direkomendasikan ke PT GMS.

\section{Distribusi Seragam}

Pada penelitian ini, metode yang digunakan untuk menghitung total jarak tempuh adalah model analitik. Metode ini lebih banyak digunakan dalam praktek, hal ini dikarenakan formula yang digunakan lebih mudah diterapkan pada spreadsheet applications yang dikenal orang lebih sederhana untuk penerapannya, kalkulasinya lebih sederhana, membutuhkan memori simpan yang lebih sedikit dibandingkan dengan metode simulasi (Roodbergen, et al., 2008). Dalam model analitik ini, lokasi item diasumsikan secara random dan mengikuti distribusi seragam (Roodbergen, et al., 2008; Sadowsky and Ten Hompel, 2011). Distribusi seragam diilustrasikan pada Gambar 2. Gambar

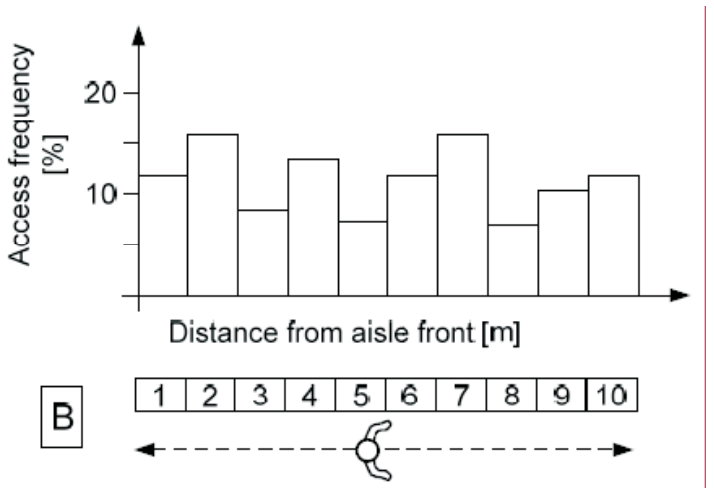

Gambar 2. Distribusi Empiris Akses Frekuensi dengan Jarak: Random Storage (Sumber: Sadowsky \& Ten Hompel, 2011)

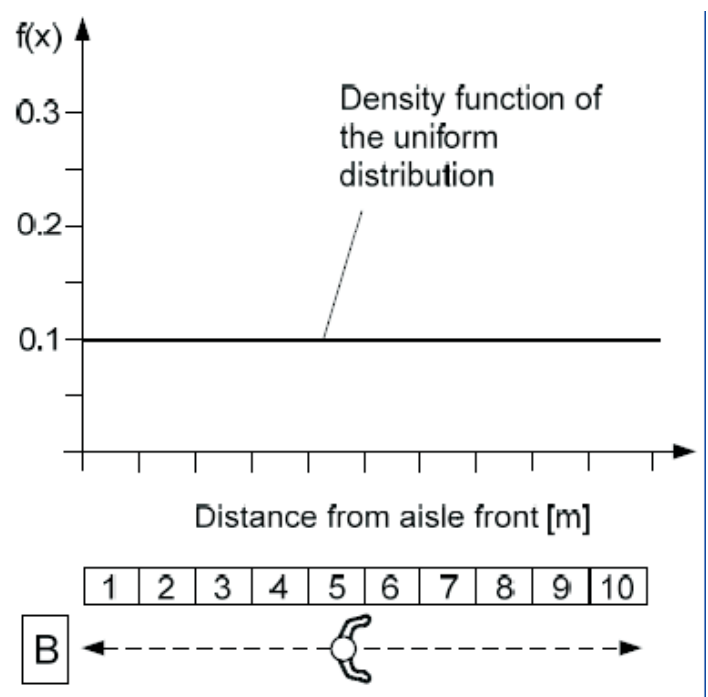

Gambar 3. Distribusi Seragam Akses Frekuensi dengan Jarak: Random Storage (Sumber: Sadowsky \& Ten Hompel, 2011)

2 menunjukkan frekuensi akses pada lokasi picking, sedangkan gambar 3 menunjukkan distribusi seragam yang merupakan pendekatan terhadap distribusi empiris.

\section{Asumsi dan Pembatasan Penelitian}

Penyimpanan random merupakan strategi simpan yang umum digunakan. Menurut Roodbergen et al., (2008), pada penelitian model analitik ini tidak mempertimbangkan faktor 


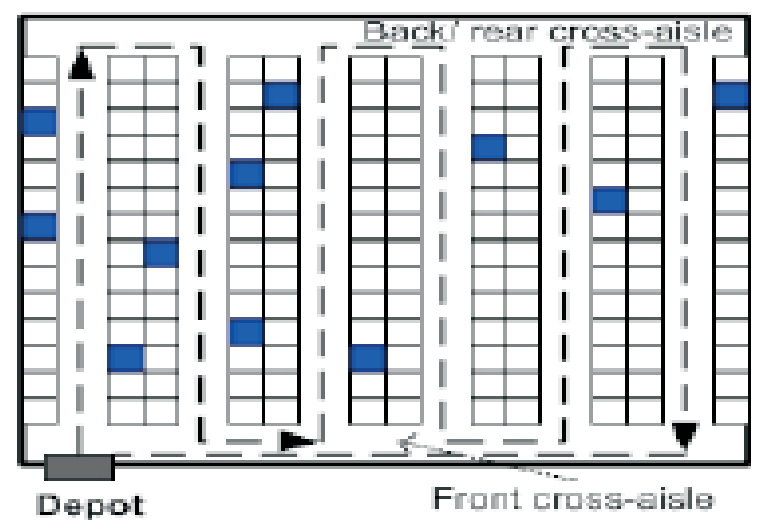

Gambar 4. Metode Routing: S-shape (Sumber: De Koster, et al., 2007)

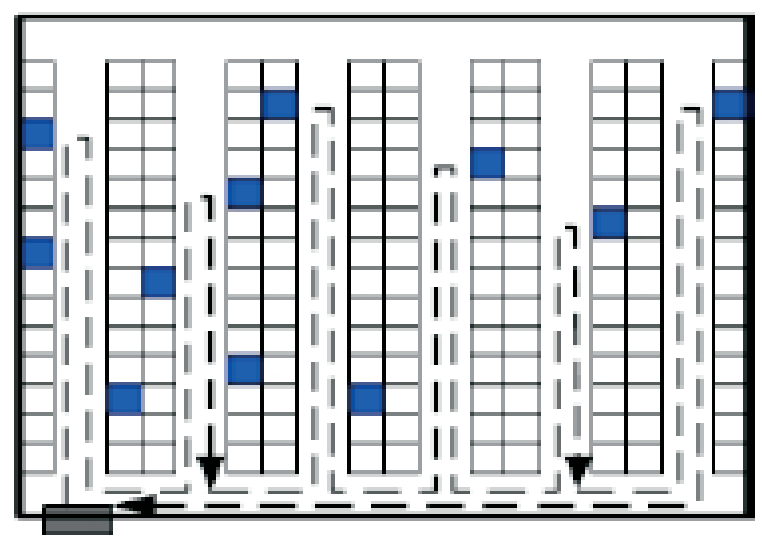

Depot

Gambar 5. Metode Routing: Return Strategy (Sumber: De Koster, et al., 2007)

lebar aisle; setiap item dapat diambil dari rak simpan tanpa memanjat ataupun menggunakan alat angkat lainnya, sehingga faktor ketinggian simpan juga tidak dipertimbangkan. Metode ini dapat digunakan pada kondisi tata letak dengan jumlah aisle dan jumlah blok berapa pun, tidak terbatas pada satu saja. Asumsi yang digunakan adalah depot terletak pada pick aisle yang paling kiri (left most pick aisle). Pada penelitian ini, metode routing yang digunakan adalah $S$ shape dan return strategy, dimana keduanya termasuk metode routing heuristic, kedua metode ini dikenal sebagai metode yang paling banyak digunakan dalam praktek sehari-hari. Ilustrasinya ditunjukkan pada Gambar 4 dan 5 .

Strategi S-Shape atau strategi traversal adalah strategi dimana picker masuk dari aisle yang pertama dari sisi depan, dan mulai melakukan kegiatan picking suatu item, dan keluar melalui dari sisi belakang pada aisle yang sama. Cara ini terus dilakukan sampai pada aisle yang terakhir, dan jika jumlah aisle-nya ganjil, maka picker akan keluar dari sisi depan pada aisle yang sama, namun jika ada aisle yang tidak memiliki item yang harus diambil, maka aisle tersebut tidak perlu dilalui (Roodbergen and De Koster, 2001). Sedangkan, strategi return adalah strategi dimana picker masuk dan keluar dari ujung aisle yang sama dan strategi ini dilanjutkan terus sampai pada aisle yang terakhir.

\section{Kalkulasi Estimasi Jarak Tempuh}

Pada penelitian yang dilakukan di PT GMS, estimasi jarak tempuh dihitung secara bertahap sesuai dengan kondisi blok dan pick aisle-nya.

- Traveling dari depot ke pick aisle yang pertama:

$$
E=W_{a} \cdot \sum_{i=1}^{n}\left((n-i)\left[\left(\frac{i}{n}\right)^{m}-\left(\frac{i-1}{n}\right)^{m}\right]\right)
$$

- Traveling through subaisle with picks:

$$
E=n . k\left[1-\left(\frac{(n . k-1)}{n . k}\right)^{m}\right]\left(\frac{y}{k}+w_{c}\right)
$$

- Koreksi jarak tempuh untuk kembali di antara subaisle:

$$
E=\frac{2 \cdot y \cdot m}{m+n \cdot k}-y ; \quad n=\text { ganjil } ; \quad \frac{m}{n \cdot k}>1
$$

- Traveling pada cross aisle dan melakukan picking :

$$
E=W_{a} \cdot \sum_{i=3}^{n} \sum_{j=1}^{k} A_{j} \cdot E_{j} \quad \text { atau } \quad E=W_{a} \cdot l
$$

Dimana:

$$
A_{j}=\left[\left(\frac{i}{n}\right)^{m}-\left(\frac{i-1}{(5)^{m}}\right)^{m}\right] \cdot\left[\left(\frac{j}{k}\right)^{m}-\left(\frac{j-1}{k}\right)^{m}\right]
$$

- Traveling balik ke depot jika semua kegiatan picking ada dalam satu blok : 


$$
E=W_{a} \cdot \sum_{i=1}^{n} \sum_{g=1}^{n}\left(A_{i 1} \cdot(g-1) \cdot\left[\left(\frac{g}{n}\right)^{m}-\left(\frac{g-1}{n}\right)^{m}\right]\right)
$$

Dimana g merupakan posisi subaisle dengan picks yang paling kanan, dan $\mathrm{g}=1$ menunjukkan posisi subaisle yang paling kanan dalam blok j.

- Total Average Travel Distance/total jarak tempuh rata-rata:

$$
T_{m}(n, k, y)=\sum_{i=1}^{1} E^{i}
$$

\section{Dimana:}

$$
\begin{aligned}
\mathrm{n}= & \text { jumlah pick aisle } \\
\mathrm{k}= & \text { jumlah blok } \\
\mathrm{y}= & \text { panjang pick aisle dan tidak termasuk } \\
& \text { lebar cross aisle } \\
\mathrm{m}= & \text { jumlah pick yang dilakukan } \\
\mathrm{w}_{\mathrm{c}}= & \text { lebar cross aisle } \\
\mathrm{w}_{\mathrm{a}}= & \text { jarak titik tengah ke titik tengah antar } \\
& 2 \text { pick aisle yang berdekatan } \\
\mathrm{i}= & \text { pick aisle yang paling kiri dan terdapat } \\
& \text { lokasi picking. Aisle akan diberi nomor } \\
& \text { dari kanan ke kiri } \\
= & \text { digunakan untuk menunjukkan blok } \\
& \text { yang terjauh dari depot dan terdapat } \\
& \text { lokasi picking. Blok akan diberi nomor } \\
& \text { dari depan ke belakang }
\end{aligned}
$$

\section{HASIL DAN PEMBAHASAN}

Kondisi tata letak di PT GMS hanya memiliki satu blok saja dengan demikian $\mathrm{k}=1$, dan jumlah aisle (n) adalah 3, panjang pick aisle adalah 4 meter, $\mathrm{w}_{\mathrm{c}}=1,5$ meter, dan $\mathrm{w}_{\mathrm{a}}=4,5$ meter. Gambar 1 menjelaskan tata letak PT GMS.

\section{Strategi Routing: S-shape / Traversal}

Strategi ini berjalan seperti ular (serpent), yakni dari depot menuju ke aisle A dan menuju ke atas (back aisle) lalu masuk ke aisle B atas (back aisle) menuju ke bawah (front aisle), dan menuju ke C. Ilustrasinya seperti Gambar 6.

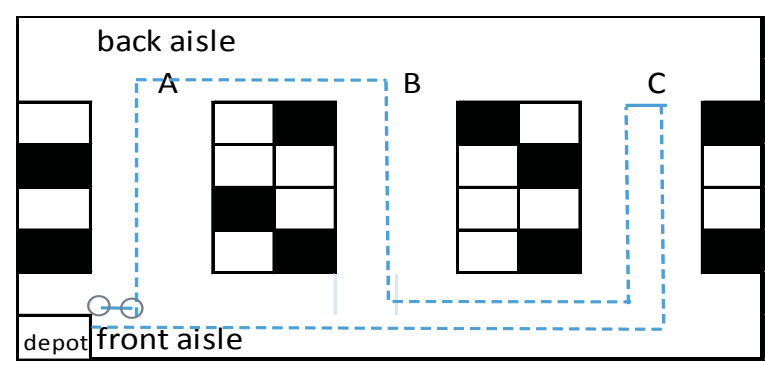

Gambar 6. S-Shape Strategy di PT GMS

- Traveling dari depot ke pick aisle yang pertama

$\mathrm{n}=1$;

$$
\begin{aligned}
E= & 4.5(3-1) \cdot\left\lfloor\left(\frac{1}{3}\right)^{10}-\left(\frac{1-1}{3}\right)^{10}\right\rfloor=0,00015 \text { meter } \\
& \mathrm{n}=2 \\
\mathrm{E} & =0,07796 \text { meter } \\
\mathrm{n} & =3 \\
\mathrm{E} & =0 \text { meter }
\end{aligned}
$$

Sehingga total E pada kondisi ini $=0,07811$ meter

- Traveling through subaisle dengan picks

$E=3,1 .\left[1-\left(\frac{(3,1-1)}{3,1}\right)^{10}\right]\left(\frac{4}{1}+1,5\right)=16,139$ meter

- Correction travel distance for turns within subaisles

$E=\frac{2,4.10}{10+3}-4=2,1535$ meter

- Traveling pada cross aisle dengan aktivitas picking

$E=W_{a} . l=4,5 \times 3=13,5$ meter

- Traveling back to the depot jika all picks terdapat dalam satu blok

a. Kondisi $\mathrm{A}_{1,1}, \mathrm{~g}=1 ; \mathrm{E}=0$ meter Kondisi $\mathrm{A}_{1,1}, \mathrm{~g}=2 ; \mathrm{E}=0,0000026$ meter Kondisi $\mathrm{A}_{1,1}, \mathrm{~g}=3 ; \mathrm{E}=0,000295$ meter

b. Kondisi $\mathrm{A}_{2,1}, \mathrm{~g}=1 ; \mathrm{E}=0$ meter Kondisi $\mathrm{A}_{2,1}, \mathrm{~g}=2 ; \mathrm{E}=0,001350$ meter Kondisi $\mathrm{A}_{2,1}, \mathrm{~g}=3 ; \mathrm{E}=0,1532$ meter

c. Kondisi $\mathrm{A}_{3,1}, \mathrm{~g}=1 ; \mathrm{E}=0$ meter Kondisi $\mathrm{A}_{3,1}, \mathrm{~g}=2 ; \mathrm{E}=0,01702$ meter Kondisi $\mathrm{A}_{3,2}, \mathrm{~g}=3 ; \mathrm{E}=1,9312$ meter Total $\mathrm{A}=2,1031$ meter 
Dengan demikian $\mathrm{E}=\mathrm{W}_{\mathrm{a}} \times 2,1031=4,5 \mathrm{x}$ $2,1031=9,464$ meter

- Total estimasi jarak tempuh rata-rata : 0,07811 $+16,2139+2,1535+13,5+9,464=41,4095$ meter

\section{Strategi Routing: Return}

Strategi ini dilakukan aisle to aisle dan pada saat selesai picking di-aisle yang pertama, maka seorang picker harus kembali ke bawah (return to front aisle). Penerapannya seperti Gambar 7. Perbedaan hanya terjadi pada tahapan kalkulasi correction travel distance for turns within subaisle dimana Return Strategy terdapat 3 aisle, dengan demikian jarak tempuh pada tahapan ini menjadi:

$$
E=\frac{2.4 \cdot 10}{10+3}-4=2,1535 \text { meter per aisle }
$$

dan metode ini ada 3 aisle sehingga menjadi: 6,4605 meter, sehingga total estimasi jarak tempuh rata-rata $=0,07811+16,2139+6,4605$ $+13.5+9.464=45,7165$ meter.

Dengan menggunakan model analitis dan routing policy S-shape maka total estimasi jarak tempuh adalah 41,4095 meter, sedangkan dengan metode return strategy, total jarak tempuh yang dihasilkan adalah 45,7165 meter. Dengan demikian strategi return menghasilkan jarak tempuh yang lebih pendek dibandingkan dengan strategi S-shape, dan lebih efisien sebesar 9,421\%. Selain routing strategy, masih ada beberapa hal yang perlu dilakukan sebagai penelitian lebih lanjut, yakni mengkaji kemungkinan dilakukan aktivitas batching - beberapa order dilakukan dalam proses picking yang sama, sehingga bisa

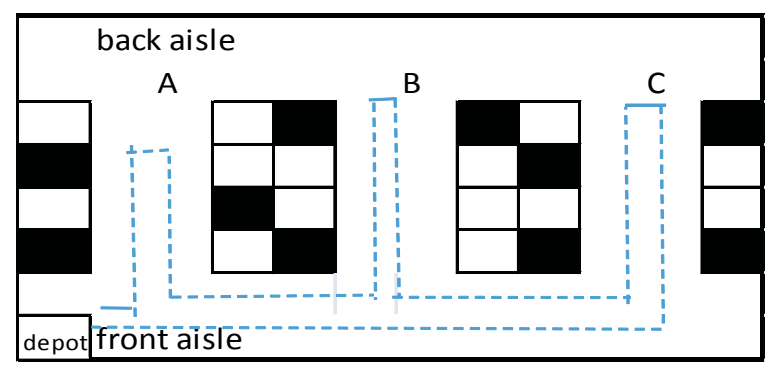

Gambar 7. Return Strategy di PT GMS dilakukan penghematan waktu lagi. Proses ini juga perlu mempertimbangkan kapasitas kereta/troli yang digunakan. Hal lain yang bisa dilakukan adalah dengan menerapkan area picking yang telah ditentukan picker-nya atau lazim disebut juga proses zoning. Dengan proses zoning, seorang picker akan lebih cepat melakukan proses picking dan bisa menghindari kemacetan-congestion pada aisle. Kedua proses ini, batching maupun zoning masih mungkin diterapkan di PT GMS.

\section{SIMPULAN}

Pada penelitian di gudang PT GMS saat ini dengan kondisi gudang yang terdiri dari satu blok dan 3 pick aisle dan menggunakan estimasi jarak tempuh rata-rata pada routing policy S-Shape/ traversal dihasilkan estimasi jarak tempuh sejauh 41,4095 meter. Sedangkan dengan metode return strategy dihasilkan jarak tempuh sejauh 45,7165 meter. Proses efisiensi waktu masih mungkin dikaji dalam penelitian dengan menggunakan proses batching dan zoning.

\section{DAFTAR PUSTAKA}

De Koster, R., Roodbergen, K.J., and Van Voorde, R., 1999. Reduction of Walking Time in the Distribution Center of De Bijenkorf, New Trends in Distribution Logistics, Springer, Berlin, 215234.

De Koster, R., Le-Duc, T., and Roodbergen, K.J., 2007. Design and Control of Warehouse Order Picking: A Literature Review, European Journal of Operational Research 182 (2), 481-501.

Dukic, G. and C. Oluic, 2007. Order Picking Methods: Improving Order - Picking Efficiency, International Journal of Logistics System and Management, 3 (4), 451-460.

Dukic, G. and Opetuk, T., 2008. Analysis of Order Picking in Warehouses with Fishbone Layout, Proceedings of ICIL, Tel Aviv, Israel.

Dukic, G., V. Cesnik, and Opetuk, T., 2010. Order Picking Methods and Technologies for Greener Warehousing, Strojarstvo, 52 (1), 23 - 31

Dukic, G. and Opetuk, T., 2012. Warehousing in the Global Supply Chain: Chapter 3: Warehouse Layout, Springer Book

Roodbergen, K.J. and R. De Koster, 2001. Routing Methods for Warehouse With Multiple Cross Aisle, International Journal of Production Research, 39 (1), 1865 - 1883. 
Roodbergen, K.J., G.P. Sharp, and I.F.A. Vis, 2008. Designing the Layout Structure of Manual Order Picking Areas in Warehouse, IIE Transaction, 40 (11), 1032-1045.

Sadowsky, W. and M. Ten Hompel, 2011. Calculation of The Average Travel Distance in a Low
Level Picker to Part System Considering Any Distribution Function With The Aisle, Logistics Journal: Reviewed, 1860-7977.

Tompkins, J.A., J.A. White, Y.A. Bozer, and J.M.A. Tanchoco, 2010. Facilities Planning, New Jersey: John Wiley and Sons. 